\title{
Violência colonial e testemunho: Para uma memória pós-abissal
}

Colonial Violence and Testimony: Toward a Post-abyssal Memory

Violence coloniale et témoignage: pour une mémoire post-abyssale

\section{Bruno Sena Martins}

\section{OpenEdition}

\section{Journals}

Edição electrónica

URL: http://journals.openedition.org/rccs/5904

DOI: $10.4000 /$ rccs.5904

ISSN: 2182-7435

\section{Editora}

Centro de Estudos Sociais da Universidade de Coimbra

Edição impressa

Data de publição: 1 maio 2015

Paginação: 105-126

ISSN: 0254-1106

\section{Refêrencia eletrónica}

Bruno Sena Martins, «Violência colonial e testemunho: Para uma memória pós-abissal », Revista Crítica de Ciências Sociais [Online], 106 | 2015, posto online no dia 28 abril 2015, consultado o 21 dezembro 2020. URL : http://journals.openedition.org/rccs/5904; DOl : https://doi.org/10.4000/rccs 5904 


\section{BRUNO SENA MARTINS}

\section{Violência colonial e testemunho: Para uma memória pós-abissal*}

O silenciamento da Guerra Colonial portuguesa/ Guerras de Libertação (1961-1974) constitui um dos elementos mais estruturantes da reconstrução democrática e pós-imperial da sociedade portuguesa. Partindo de uma extensa recolha de histórias de vida de "deficientes das Forças Armadas", o presente texto procura analisar as lutas pelo sentido trazidas pelas suas narrativas. Por um lado, procuramos perceber os termos de um confronto entre uma memória da violência, corporalmente inscrita, e a denegação da violência colonial no senso comum do Portugal democrático. Por outro, procuramos compreender de que modo a noção de uma guerra evitável e injusta, crescentemente sedimentada após o seu ocaso, cria um paradoxo para aqueles que, tendo sido parte de uma força agressora, se configuram como vítimas.

Palavras-chave: colonialismo; deficientes das Forças Armadas; Guerra Colonial; memória; violência.

\section{Introdução}

A Guerra Colonial ${ }^{1}$ constitui um momento fundador da realidade sociopolítica do Portugal contemporâneo. Desde logo, porque a transição democrática encetada com o 25 de Abril está intimamente ligada ao conflito que entre 1961 e 1974 opôs as Forças Armadas portuguesas aos movimentos independentistas em Angola, Moçambique e Guiné-Bissau. Na verdade, a revolução que em 25 de Abril de 1974 foi levada a cabo pelo Movimento das Forças Armadas resulta em grande medida do desgaste produzido pelo

\footnotetext{
* Este trabalho é financiado por ERC/FP7 (projeto "ALICE, espelhos estranhos, lições imprevistas" - agreement n. ${ }^{\circ}$ 269807), por Fundos FEDER através do Programa Operacional Factores de Competitividade (COMPETE) e por Fundos Nacionais através da Fundação para a Ciência e a Tecnologia (FCT) no âmbito dos projetos PTDC/CS-SOC/118305/2010-FCOMP-01-0124 -FEDER-019877 e PTDC/AFR/121404/2010-FCOMP-01-0124-FEDER-019531.

1 Tendo em conta que o mesmo conflito é diferentemente designado ora como Guerra Colonial ora como Guerra de Libertação, consoante o lado da contenda que o evoca, optaremos aqui pela primeira designação de "Guerra Colonial”, em conformidade com o campo de análise sobre o qual nos debruçamos: a sociedade portuguesa.
} 
arrastamento da Guerra. Estamos perante um conflito com profundas consequências humanas, pelas marcas deixadas nos combatentes dos diferentes lados da contenda, cujas vidas foram significativamente atravessadas pela experiência da Guerra, e pelas incontáveis vítimas civis, sujeitas que foram a massacres, deslocamentos forçados e a violências de toda a sorte.

A magnitude do impacto da Guerra Colonial traduz-se, face à dimensão e recursos de Portugal, de várias formas. Em primeiro lugar, pela existência de três frentes de combate - Angola, Guiné-Bissau e Moçambique -, distantes de Lisboa e distantes entre si. $^{2}$ Em segundo lugar, traduz-se no elevado número de homens que foram colocados ao serviço da manutenção do império colonial, tanto através de recrutamento na metrópole, como por via de recrutamento local nas colónias: ${ }^{3}$

Desde o fim de 1961 até 1974, o número de pessoal do Exército em África aumentou de 49422 para 149 090, representando uma taxa anual média de crescimento de cerca de 11 por cento. [...] Portugal foi forçado a mobilizar cerca de 1 por cento da sua população para combater em África e não podia simplesmente manter esta drenagem nacional de pessoal. Numa base percentual, tinha mais homens em armas do que qualquer outro país, à excepção de Israel. (Cann, 2005: 109, 126)

Assim, resulta desconcertante perceber o lugar residual que a Guerra Colonial ocupa no senso comum produzido e reproduzido sobre o que sejam a história recente e a identidade portuguesas ou, mais amplamente, sobre o profundo impacto do ciclo colonial no tecido social português. ${ }^{4}$ Neste texto, auscultando os homens que viveram e fizeram a Guerra, em particular os que ficaram marcados por uma deficiência no seu curso, refletimos sobre o lugar que a violência colonial ocupa na memória e na experiência social em Portugal.

Compreender a disjunção que em Portugal se sedimentou entre quem fez a Guerra e a ordem sociopolítica e cultural que a silenciou ao absurdo,

\footnotetext{
2 "Angola, cenário da acção inicial em 1961, localiza-se na costa sudoeste de África. Luanda, a principal cidade e porto de reabastecimento, dista, por via aérea, aproximadamente 7300 quilómetros de Lisboa. A Guiné, local do segundo levantamento, a partir de Janeiro de 1963, localiza-se na costa oeste-africana, a cerca de 3400 quilómetros por via aérea. Moçambique, palco da terceira revolta, em Setembro de 1964, e o seu principal aeródromo de reabastecimento, na Beira, encontram-se a 10300 quilómetros de Lisboa. Estas distâncias agigantavam o problema logístico e provocavam um desgaste enorme nos meios de transporte [...]” (Cann, 2005: 24).

3 Conforme refere Carlos Matos Gomes, aquando do final da Guerra Colonial, "dos cerca de 170 mil homens nos três teatros de operações, cerca de 83 mil eram de recrutamento local, o que representa aproximadamente 48\%" (2013: 127).

${ }^{4}$ Dado bem evidente no importante contingente de populações brancas instaladas nas colónias - sobretudo nas colónias de povoamento, Angola e Moçambique - ou na magnitude da vaga migratória dos ditos retornados, após o 25 de Abril (cf. Castelo, 2007; Meneses e Gomes, 2013).
} 
implica, neste texto, reconhecer uma política da memória que vigorou e vigora no Ocidente em relação à experiência colonial e à violência que a instaurou e perpetuou. Pulsamos uma memória que, descendendo da casa do "pensamento abissal moderno" (Santos, 2007), define como princípio civilizacional, tão desesperado como eficaz, o esquecimento das atrocidades que os países europeus perpetraram nos territórios colonizados.

Desta forma, recrutando a noção de "pensamento abissal" de Boaventura de Sousa Santos $(2007 ; 2014)$ identificamos dois sistemas de significado, velando sobre a Guerra Colonial em sentidos opostos: a memória abissal e a memória pós-abissal. A memória abissal constitui um sistema de significado, dominante, no qual, durante décadas, a violência da Guerra Colonial foi ostensivamente apagada, silenciada e empurrada para o esquecimento. Este sistema de significado é aquele que se concerta com as representações míticas sobre a identidade portuguesa, nomeadamente a ideia, ainda vigente, de Portugal como uma potência colonial não violenta ou como um país de brandos costumes. Identificamos outro sistema de significado, a memória pós-abissal, subalterno na sociedade portuguesa, no qual a Guerra Colonial emerge não só como um facto incontornável da história recente de Portugal, desalojando o lugar ocupado por "excesso mítico de interpretação" (Santos, 1999: 49), mas como um fator que persiste marcando uma paisagem social no presente.

Assumimos uma perspetiva que, incidindo mormente na experiência dos Deficientes das Forças Armas (DFA) que regressaram a Portugal após a Guerra, se encontra situada por um análogo trabalho de recolha junto dos combatentes africanos residentes em Moçambique, tanto os que lutaram pela independência de Moçambique (combatentes da Luta de Libertação Nacional), como aqueles que, tendo feito parte do Exército português, após a Guerra cumularam à deficiência o estigma da traição. Não sendo este o espaço para analisar a singularidade de cada um destes percursos, cabe sublinhar que os diferentes lados do pós-Guerra se inscreveram em processos histórico-políticos sumamente distintos. ${ }^{5}$

\footnotetext{
5 Desde logo, porque enquanto Portugal pôde usufruir da paz, em Angola e Moçambique tiveram lugar as novas guerras, marcadas por um elevado grau de violência, que se repercutiria fortemente sobre as populações. As ditas guerras civis de Moçambique e Angola acabariam por se arrastar no tempo e só chegariam ao seu termo, respetivamente, em 1992 e 2002. Como refere João Paulo Borges Coelho: "[...] a guerra colonial foi muito mais que um mero conflito de ocupação datado dentro das balizas cronológicas que normalmente lhe são atribuídas, induzindo, pelo contrário, sobretudo na sua fase final após 1968, uma militarização da sociedade que nos dá razões para afirmar que por trás desse conflito se escondia já o germe de um conflito civil” (2003: 176-177).
} 
Por exemplo, no que à contextualização narrativa da deficiência diz respeito, é suficientemente ilustrativo percebermos como nas histórias dos ex-combatentes da FRELIMO a deficiência surge como signo de um sacrifício conducente à conquista da autodeterminação e ao fim do jugo colonial, como um signo de uma narrativa heroica do sangue fundador de uma nação independente (ainda que o devido reconhecimento político desse sacrifício seja um ponto de acesa controvérsia). Num tal quadro, em que a Guerra ganha o nome de "Luta de Libertação Nacional", a relação entre deficiência, memória social e narrativa pessoal encontra-se constituída em termos muito diversos daqueles que são oferecidos pela realidade portuguesa. Neste texto, centramo-nos no contexto português para analisar a persistência de uma construção "ainda colonial" nos próprios mecanismos que, no presente, fazem da violência colonial algo suficientemente longínquo ou insignificante para que se possa menorizar ou denegar.

\section{Os deficientes das Forças Armadas}

Não é difícil supor as enormes repercussões de um conflito em que o Exército português terá mobilizado mais de um milhão de homens ao longo de 13 anos, em que terão morrido 8290 soldados, e em que o número de combatentes que adquiriram deficiências permanentes (físicas e psicológicas) se estima nas muitas dezenas de milhar (ADFA, 1999).

Nenhuma instância materializa tão bem o abandono e exclusão social vividos pelos DFA como o invariável espaço de moratória destes ex-combatentes no seu regresso da Guerra: o Hospital Militar, em Lisboa. Como a gravidade das situações clínicas o justificasse, ou porque o acesso a cuidados médicos fosse escasso, era tal a quantidade de feridos face às estruturas de resposta, que muitos DFA ficavam longo tempo, às vezes anos, no Hospital Militar de Lisboa. A toponímia de algumas das valências do hospital é esclarecedora. O designado "Depósito de Indisponíveis" exprime bem a sensação de abandono expressa por muitos dos ex-combatentes que ali viveram (sentindo que ali foram literalmente depositados); já o “Texas”, designação informal popularizada do anexo do Hospital Militar Principal, ${ }^{7}$ refere o ambiente de caos e desordem generalizada (qual Far-West) que se vivia.

Os hospitais situados nas colónias, para onde muitos dos DFA foram inicialmente evacuados, permitiam já perceber o quadro de exaustão das estruturas médicas, perante a intensidade da Guerra:

\footnotetext{
${ }_{6}$ Situado no Largo da Graça.

7 Situado na Rua da Artilharia 1.
} 
Eh, pá... no espaço de três, quatro horas, já estava em Bissau. Estava em Bissau e partir daí... [...] No Hospital de Bissau, e aí é que eu tive noção de que aquilo era uma guerra a sério!... Eu quando cheguei ao bloco operatório, no corredor - parece que estou a ver - era só indivíduos embrulhados em cobertores, a gritar, à espera de vaga. Entravam para os blocos os mais prementes. E quando cheguei ao Bloco, na pedra em que me deitaram... Pronto. Ainda vi, debaixo da pedra, alguidares de carne humana... Carne! Cortada...! E aí fiquei, realmente traumatizado. Se já vinha traumatizado, mais traumatizado fiquei. E depois era a toda a hora os helicópteros a chegar com gente ferida... (Armindo, ${ }^{8}$ entrevista)

\section{Uma vez no Hospital Militar, em Lisboa, os DFA viveram um aparatoso} abandono imposto pela escassez de recursos médicos, de pessoal e de espaço:

Olhe, o confronto com o Hospital Militar de Lisboa não podia ser pior do que o que foi. Eu cheguei à Estrela, como the disse, vim de noite, fui para as urgências... Depois, fui para a medicina de oficiais. Na medicina de oficiais, estavam lá todos aqueles alferes milicianos vindos da guerra sem braços, sem pernas, e tal... E cegos na altura estávamos lá três. Três cegos. Era eu, o falecido Maurício, que tem o nome deste auditório e o Silvério, que é um indivíduo cego e sem mãos. Mandaram-me lá para um quarto sem me dar qualquer apoio psicológico, sem me ensinar nomeadamente a ir da cama à casa-de-banho para ser autónomo. Não me ensinaram nada. Pronto, parecia um... Digamos, eu tive a sensação... Tive, tenho ainda hoje, essa sensação de que eu era um... Pronto, era um fardo, era uma coisa que já não era útil para a guerra, que tinha ficado cego e pronto. A retaguarda era assim que nos tratava: um lixo. Eh pá, e uma pessoa fica cega, eu, pelo menos, passei por isso, eu pensava que nem sabia comer, nem que eu sabia comer sozinho, nem que conseguia andar sozinho... As enfermeiras iam lá levar... Enfermeiras ou ajudantes, não sei. Iam-me levar a comida e diziam assim: "Senhor alferes, está aqui a comida." Assim ao fundo da cama havia uma mesinha, punham-me lá a comida e depois, se eu quisesse ia comer. (Rogério, entrevista)

As histórias de desamparo vividas no Hospital Militar cruzam-se com muitos relatos de vidas de álcool e prostitutas na noite de Lisboa, achadas por muitos daqueles que estavam em condição de sair como a única "terapia” realmente acessível. Neste contexto, os DFA foram igualmente sujeitos a uma lógica deliberada de invisibilização, estratégia que o regime ditatorial

\footnotetext{
${ }^{8}$ Os nomes dos entrevistados são ficcionados. Todas as entrevistas respeitaram o consentimento informado, tendo sido providenciados todos os elementos sobre objetivos das entrevistas, do uso a ser dado aos testemunhos partilhados e respetivas condições de publicitação.
} 
usou para minorar o impacto das sequelas da Guerra na sociedade portuguesa, tanto no que se refere aos mortos como aos feridos. Por exemplo, as urnas com os soldados mortos eram sempre tiradas dos barcos de noite, sendo depois transportadas de modo discreto para as suas comunidades de origem (Maurício, 1994; Antunes, 1996). Do mesmo modo, havia regras para que os DFA que estavam nos hospitais não saíssem para a rua em grupo, para não criarem alarme social:

Sim, sim, vamos lá ver, três ou quatro indivíduos, decidíamos ir jantar, não podíamos sair três, quatro indivíduos de cadeira de rodas, não é? Saía um de cada vez, chamávamos os táxis, nós tínhamos um esquema entre nós para chamar os táxis, depois eu ia num táxi, o taxista arrumava a cadeira atrás [...] E depois encontrávamo-nos todos! Porque, vamos lá ver, eles não deixavam que quatro de cadeira de rodas saíssem à porta do hospital. (Eduardo, entrevista pessoal)

Num certo sentido, a invisibilidade e abandono a que os DFA foram sujeitos logo após a Guerra, no Hospital Militar, prefigura a exclusão que viriam a sofrer no Portugal democrático. Estamos perante uma liminaridade perpetuada pelo encontro de duas formas de exclusão: a descontinuidade imposta pela experiência de deslocalização produzida pela Guerra Colonial e a marca vivencial imposta pela deficiência. No entanto, o Hospital Militar é, igualmente, o espaço de capacitação e resistência. Foi lá que germinou a ideia de criação de uma associação que, após o 25 de Abril, se viria a substanciar na Associação dos Deficientes das Forças Armadas (ADFA). Estamos perante a communitas de que nos fala Victor Turner (1967), o laço de solidariedade horizontal criado por sujeitos liminares colocados à margem da sociedade:

Fui para a cirurgia de oficiais, na Estrela. No hospital militar da Estrela, onde vou encontrar oficiais amputados, de pernas, de braços. A cirurgia de sargentos era mesmo ao lado, onde eu vejo passar furriéis amputados dos braços, paraplégicos, tetraplégicos, cadeira de rodas... $\mathrm{Na}$ oficina de oficiais, na liga dos tetraplégicos... No quarto ao lado do meu estava um cadete tetraplégico, mais um alferes paraplégico, e eu disse assim "alto lá! Isto é de facto o mundo a que eu pertenço agora! Mas é um mundo habitado!”. Eu já não estou sozinho nesse mundo, não é? Há por aqui outras pessoas! [...] As pessoas, apesar de tudo, viviam! Não é? Viviam, e brincavam, e contavam anedotas e... enfim, e eu comecei a entrar nesse mundo também, não é? E a viver! E a viver. Digamos que isto é um mundo fechado. É um mundo de pessoas com ferimentos graves, profundos. E com deficiências profundas. O pessoal hospitalar, desde os médicos aos auxiliares, passando pelo pessoal de enfermagem, 
lidava connosco de uma forma humana, não é? De uma forma, enfim, encorajadora até. Pronto, era aquele mundo. Mas quando saio da cirurgia de oficiais e vou para a Medicina de Oficiais, para o edifício principal da Estrela, daí passo a sair. Portanto, enfim, já não precisava de estar... já não estava acamado, já não precisava de estar... (Mariano, entrevista pessoal)

Esta partilhada experiência de abandono, de falta de cuidados médicos, de compensações, de horizontes de reinserção social, efervesceu como revolta no Hospital Militar de Lisboa e seria materializada na Associação dos Deficientes das Forças Armadas, criada em 14 de maio de 1974.

Após o 25 de Abril, face à continuada negligência que os deficientes de guerra vinham percebendo, a ADFA cresce da convicção de que a revolução não alterara a negligência do poder político. Tratava-se, pois, da luta pela inscrição de uma nova agenda reivindicativa num clima revolucionário em que expectativas exaltantes em relação ao futuro estabeleceram uma ordem social pouco afeita à memória da Guerra. Nas palavras de um dos entrevistados:

Veio o 25 de Abril, foi assim uma espécie de primavera, depois de um longo inverno e isso falar de inverno ou primavera não é muito conveniente, então isso ficou esquecido durante muito tempo. (Heitor, entrevista pessoal)

De facto, a evocação de momentos de conflito, em que o voo pelo passado carrega igualmente complexos processos de atribuição de sentido ou imputação de culpa, tende a criar resistências à evocação que, no limite, sustêm a ordem social (Connerton, 1989; LaCapra, 2001; Barkan, 2001). Como refere Ian Hacking, a elisão da guerra é um mecanismo muito comum: "As nações proverbialmente gostam de esquecer os estilhaços das suas guerras passadas" (1996: 78). No entanto, para que possamos perceber como operam estes processos de esquecimento, importa reconhecer de que modos tais "estilhaços" são inscritos nas histórias particulares que os ocultam. No caso de Portugal, tanto quanto perceber os mecanismos que durante a ditadura justificaram a Guerra, ao mesmo tempo que minimizavam a sua real dimensão, cabe entender de que forma o 25 de Abril veio a consagrar tal conflito como inexistente ou de escusada memória.

No entanto, seja para os civis que sofreram as suas consequências, seja para aqueles ex-combatentes mais fortemente afetados pelas consequências da Guerra - como é o proverbial caso dos DFA - esse desejo avultava como uma radical impossibilidade, tal o manto com que a violência da 
Guerra se inscreveu nos seus corpos e nas suas memórias. ${ }^{9}$ Relativamente aos DFA, tudo se passa numa contradição entre o "excesso de memória" destes ex-combatentes (na medida em que carregam as marcas biográficas, psicológicas e corpóreas da Guerra Colonial) e o manifesto silêncio da sociedade portuguesa face a um tão significativo conflito. Assim, a fim de entendermos cabalmente este desencontro, convém perceber alguns fatores e conjunturas que potenciaram o ativo de apagamento da Guerra Colonial da memória social portuguesa.

Em primeiro lugar, importa perceber que o Movimento das Forças Armadas, responsável pela revolução, nasce do descontentamento de oficiais de patente intermédia em relação à Guerra. Ou seja, o poder que se estabelece no 25 de Abril é fortemente marcado pela presença de militares que, a despeito das suas posições críticas - corporativas ou políticas - em relação à Guerra, foram parte ativa no esforço de guerra. Assim, o tema da guerra implicava os mesmos agentes que se tornaram responsáveis pela revolução e que assumiram inequívoco protagonismo na transição democrática. Se ao regime ditatorial cabe, inequivocamente, a responsabilidade política pela assunção de guerra, o regime democrático nasce pela mão de um movimento de militares que, tendo estado implicados na Guerra, estavam longe de a poder ver de um modo inteiramente distanciado.

Em segundo lugar, sendo verdade que a evocação condenatória da Guerra estava constrangida pelas figuras que protagonizaram a mudança de regime, pouco espaço haveria para a sua evocação através da reivindicação heroica. Vários fatores explicam este facto, a saber: a noção de que, mesmo do ponto de vista estratégico-militar, se tratou de uma guerra perdida ${ }^{10}$ (ou, pelo menos, que não poderia ser ganha); ${ }^{11}$ a deposição dos poderes políticos que sustentaram a bondade patriótica da Guerra; e a condenação internacional de uma Guerra que, no seu esforço de deter a vaga de descolonizações, percebidas como inevitáveis, se veio conceber, quase consensualmente, como absurda e anacrónica. Portanto, a "comunidade imaginada" (Anderson, 1983) que em Portugal se constituiu após o 25 de Abril extirpou a Guerra do seu passado, não obstante ser um facto recente com enorme impacto ou,

\footnotetext{
9 A guerra impõe com particular prevalência nos combatentes o surgimento deferido de memórias disruptivas, próximas daquilo que a nosologia paulatinamente veio a reconhecer como "Transtornos/ Desordens/Distúrbios de Stress Pós-Traumático” (DSPT). O DSPT só ganhou estatuto nosológico oficial em 1980, na terceira edição do Diagnostic and Statistical Manual of Mental Disorders. Em Portugal, só a partir de 1986 é que, progressivamente, os diagnósticos de DSPT se estabeleceram na análise das desordens de alguns combatentes (Quintais, 2000; Albuquerque e Lopes, 1994).

${ }^{10}$ Facto mais flagrante em Moçambique e na Guiné-Bissau do que em Angola.

${ }^{11}$ Como afirma John Cann, a Guerra não poderia ter sido ganha militarmente dado que "a posição de Portugal em África era insustentável desde o início” (2005: 213).
} 
se quisermos, talvez exatamente por causa da magnitude do impacto traumático que dela resultou.

Paul Ricoeur exprime bem o desafio que o testemunho coloca conquanto nos remete para "testemunhas históricas" cuja capacidade de demover os lugares comuns - acerca da sociedade e do seu passado - muitas vezes corresponde à solidão da memória:

[...] em última análise, o nível elementar da segurança da linguagem numa sociedade depende da confiabilidade, e portanto na prova biográfica de cada testemunha, caso a caso. É contra este fundo de suposta confiança que emerge, tragicamente, a solidão das "testemunhas históricas" cuja experiências extraordinárias dificultam a capacidade para uma compreensão habitual e ordinária. Mas existem também testemunhas que nunca encontram uma audiência capaz de as ouvir ou de escutar o que têm a dizer. (Ricoeur, 2004: 167)

A solidão das testemunhas, neste caso, resulta do modo como o silenciamento da Guerra produz como "extraordinárias" as experiências - afinal tão comuns - daqueles cujas biografias ficaram marcadas pelo irremediável da guerra. Mais do que a confiabilidade, o que aqui avulta é, pois, a falta de interlocutores que validem as violências impostas pela Guerra. A possibilidade de partilha do trauma e da violência é, assim, um elemento essencial para a ressignificação do sujeito isolado pelo excesso de memória:

O trauma partilhado por uma comunidade inteira cria um espaço público potencial para reenunciação. Se uma comunidade concorda que os eventos traumáticos aconteceram e incorpora este facto na sua identidade, então a memória coletiva sobrevive e a memória individual pode encontrar um lugar (ainda que transformado) dentro dessa paisagem. (Kirmayer, 1996: 189-190)

Estamos perante a busca de hospitalidade à memória e ao reconhecimento das identidades passíveis de se afirmarem dentro de uma comunidade, numa transformação recursiva entre sujeito e narrativa social:

O espaço social ocupado por histórias de populações marcadas por feridas pode permitir que se quebrem os códigos culturais rotineiros veiculando contradiscursos que ponham em causa os significados adquiridos acerca de como as coisas são. Dessas histórias desesperadas e subjugadas pode bem surgir o apelo que altere os lugares comuns - tanto ao nível da experiência coletiva como da subjetividade individual. (Das e Kleinman, 2001: 21) 
A memória da Guerra Colonial constitui um espectro que assola, ainda, a sociedade portuguesa. Para as representações hegemónicas sobre o Portugal pós-imperial os DFA constituem algo de uma presença fantasmática, corpos estranhos à narrativa social dominante cujas vozes remetem para um tempo, radicalmente inscrito no passado ou determinado como não existente.

Para os DFA, a deficiência emerge como o segundo fator na produção de uma exterioridade em relação à sociedade portuguesa. Conforme fica patente nos diversos relatos sobre o regresso a Portugal e sobre a busca de itinerários de inclusão social, os Deficientes das Forças Armadas, não obstante algumas garantias que foram conquistadas na legislação compensatória, confrontaram-se e confrontam-se com a fortíssima discriminação social a que as pessoas com deficiência estão expostas na nossa sociedade. Assim, mesmo após uma reconstrução pessoal e coletiva em que a difícil herança da Guerra é assumida como parte de percurso a ser empreendido, permanece uma linha de desigualdade social que junta, excluindo, os DFA às demais pessoas com deficiência. A realidade das pessoas com deficiência em Portugal persiste marcada por fortíssimas condições de marginalização social e exclusão económica (Martins, 2006). Tal perpetuação acontece a despeito das sucessivas transformações legislativas e das políticas sociais que foram sendo introduzidas nas últimas décadas.

Reside esse entrave numa conceção de deficiência que se encontra profundamente ancorada a uma "narrativa da tragédia pessoal" (Oliver, 1990), uma gramática cultural que permeia as vidas das pessoas com deficiência qual poderoso referente que cria as condições da sua verdade:

[...] de um momento para o outro apanho-me cá fora, deparo com todas as barreiras possíveis e imaginárias, barreiras arquitetónicas, barreiras humanas, de pessoas que encaravam a nossa situação chamando-nos "coitadinho" "desgraçadinho", isto custava um bocadinho a ouvir, quer dizer, e depois quando chegávamos a algum edifício ficávamos a olhar para os degraus, quando não há barreiras arquitetónicas - ainda hoje isso acontece - uma pessoa parece que se "esquece" da deficiência, mas quando as encontra parece que há ali um sininho logo a trabalhar [...] era muito difícil e mesmo os próprios táxis para me levarem daqui para acolá, havia um ou outro taxista que punha objeções por causa da cadeira... (João, entrevista)

À semelhança do que acontece noutras sociedades, as pessoas com deficiência em Portugal estão sujeitas a enormes obstáculos à sua participação social: atitudes e conceções discriminatórias, barreiras arquitetónicas e comunicativas, apoio inadequado no acesso à educação, critérios 
excludentes no acesso ao mercado de trabalho, salários baixos e condições de trabalho precárias. Se é verdade que as estruturas e valores excludentes das pessoas com deficiência são comuns em muitas sociedades, este aspeto - relativamente a outros países - é agravado em Portugal pela fragilidade do movimento social de pessoas com deficiência (Martins, 2006; Fontes, 2009). Trata-se de um movimento cuja capacidade reivindicativa é, ainda, muito reduzida, porventura uma duradoura consequência do controlo que o Estado exerceu sobre a sociedade civil durante a longa ditadura do século XX (Santos e Nunes, 2004). Ao contrário do que acontece, por exemplo, no Reino Unido ou nos Estados Unidos da América, onde a politização da deficiência tem tido um importante impacto (Barnes, 2003; Hahn, 2002), em Portugal prevalecem as abordagens fatalistas que individualizam a deficiência e naturalizam as suas implicações. Dadas as condições de vida das pessoas com deficiência, as organizações que as representam, desde o início, têm investido mais na provisão de serviços, funcionando como uma extensão do Estado social. Desse modo, os recursos humanos disponíveis nas organizações tendem a ser desviados de um posicionamento político passível de transformar a sociedade - naquilo que são as suas estruturas discriminatórias das pessoas com deficiência.

Neste particular, cabe reconhecer o importantíssimo papel da ADFA enquanto parte ativa na reivindicação política. $\mathrm{Na}$ verdade, muitos dos direitos legislativos adquiridos pelas pessoas com deficiência após o 25 de Abril foram inicialmente conquistados pelos deficientes de guerra e só mais tarde alargados à generalidade das pessoas com deficiência. No entanto, podemos dizer que a ação da ADFA tem sido mais contundente na demanda de compensações financeiras pelas deficiências adquiridas na Guerra, do que na construção de uma sociedade inclusiva em que as pessoas com deficiência possam participar de uma forma cabal.

A luta assumida pelos Deficientes das Forças Armadas entre 1974 e 1975, sob diversas formas - manifestações, tomada de espaços públicos, etc. -, granjeou à ADFA um reconhecimento público e político que se mostrou essencial tanto para a legislação que viria a ser promulgada para garantir reparações, como para a afirmação da ADFA enquanto um interlocutor merecedor da atenção do poder político. Como dizíamos, a luta dos DFA teve, sem dúvida, um importante efeito em muita da legislação e das estruturas de reabilitação que depois seriam alargadas às demais pessoas com deficiência. Esta associação detém hoje cerca de 14 mil associados e, além da representação política dos interesses dos DFA, dos direitos e reparações, presta serviços aos associados e suas famílias, fundamentalmente ao nível do apoio jurídico e administrativo, mas também na vertente médico-social. 
Devido à especificidade das reivindicações da ADFA, as suas conquistas e agendas não são inteiramente transponíveis para as demais pessoas com deficiência. Ou seja, o elevado poder reivindicativo da ADFA na defesa intransigente dos direitos dos DFA, seja pelo modo como historicamente soube dar prova da sua capacidade de mobilização, seja pela elevada dívida simbólica que as deficiências adquiridas ao serviço da nação colocam ao Estado, terá feito mais pelas compensações atribuídas aos DFA do que, propriamente, por transformação social capaz de criar uma sociedade inclusiva para as pessoas com deficiência.

\section{Violências na carne}

Quando nos debruçamos no modo como a Guerra surge nas histórias dos DFA, confrontamo-nos com as múltiplas instâncias da violência: violências sofridas, violências testemunhadas ou perpetradas. Em relação à generalidade dos ex-combatentes, os testemunhos dos DFA têm de singular a invariável existência de um evento ou experiência que, engendrando uma deficiência, estabelece um antes e depois nas suas vidas. ${ }^{12}$ Nas histórias a que tivemos acesso, a experiência de um ferimento para quem o sofre surge, quase sempre, mediada ou antecipada pelo contacto com as experiências prévias de companheiros mutilados em combate:

Quando acordei apercebi-me que estava sem uma perna, fiquei 1 segundo ou $2 \mathrm{sob}$ o efeito do sopro da explosão, mais nada do que isso, fiquei em estado de choque, obviamente, depois havia pessoas ligeiramente feridas, assim com estes estilhaços no rosto e tal, pela projeção da areia, era uma mina antipessoal se não também tinha desaparecido um ou outro. O helicóptero demorou pouco tempo a vir, diga-se, em abono da verdade, que a força aérea fez um trabalho exemplar lá e os helicópteros para as evacuações dos feridos demoravam muito pouco tempo, mesmo a dezenas de quilómetros, sempre com guerra a acontecer por todos os lados, um helicóptero ia lá passado não sei quantos minutos, a mim pareceu-me muito tempo, obviamente, mas bem vistas as coisas foi rapidamente. E não há mais nada a contar, quer dizer foi assim, uma mina que rebentou, é uma coisa traiçoeira, absolutamente estúpida, uma coisa de que nós não nos apercebemos de nada, apagamos simplesmente e acordamos para uma realidade, bom essa bastante chocante, que é ver uma perna como um osso de um frango cozido com o osso à vista, com a perna em tiras de pele e de carne e não sei quê, é uma visão horrorosa, à qual nós já nos tínhamos habituado.

\footnotetext{
${ }^{12}$ Alguns testemunhos recolhidos junto dos deficientes da Forças Armadas, aqui em análise, estão na base do filme documental: A bospitalidade ao fantasma: memórias dos deficientes das Forças Armadas, disponível em https://youtu.be/aF5vWj5T5uY.
} 
Já tinha visto, por antecipação já sabia como é que as minhas pernas iam ficar, de uma pessoa que pisa uma mina, é um terror absoluto apesar de nós sabermos que corremos esse perigo diariamente mas para podermos sobreviver a gente ultrapassa e tem que ultrapassar esse medo. (Heitor, entrevista)

Na gramática da violência a que os combatentes estiveram sujeitos durante a Guerra, os momentos que inscrevem a deficiência nas suas vidas não são, em si, necessariamente, excecionais. O convívio com corpos de companheiros mutilados, com o medo do rebentamento de uma mina antipessoal ou com a incerteza das emboscadas, de algum modo trivializava os episódios que puderam suscitar marcas irreversíveis. No entanto, o facto de essa violência se inscrever de forma definitiva no próprio corpo, como inapagável marca da existência, carrega, do ponto de vista da experiência vivida e da biografia, uma singularidade que é, em larga medida, aquela que se liga à incomensurabilidade - ou difícil comunicabilidade - da experiência incorporada (French, 1994). As implicações da deficiência não são separáveis dos quadros culturais e lógicas de poder em vigor nas diferentes sociedades (Ingstad e Whyte, 1995; Martins, 2013), no entanto, tal não nega o quanto a Guerra trouxe para muitos dos DFA, por via de ferimentos ou de memórias disruptivas, transformações transgressoras - corpóreas, ontológicas, fenomenológicas - que largamente transcendem as possibilidades de "restituição" social.

Estamos, pois, em face de realidades que fogem às apreensões discursivas e onde o corpo vivido assoma com incontornável vigor. A esta dimensão do sofrimento pessoal, eminentemente corporal, não totalmente apreensível na sua relação com elementos sociais, chamamos "angústia da transgressão corporal” (Martins, 2006; 2008). A angústia da transgressão corporal refere-se à vulnerabilidade na existência dada por um corpo que nos falha, que transgride as nossas referências na existência, as nossas referências no modo de ser-no-mundo. Assim entendida, a angústia da transgressão corporal concita-nos a reconhecer dimensões de dor, sofrimento e ansiedade existencial onde, contra sedimentada negligência, o corpo vivido, o conhecimento incorporado e as emoções adquirem estatuto nobre nas reflexões socioantropológicas.

Falamos de sofrimentos e frustrações que há décadas são parte das vivências quotidianas dos DFA:

Mas isto é uma coisa diária; ainda hoje, ainda hoje... Eu estava a pôr uns papéis... num envelope... e queria pôr e não conseguia, a mão não dava, não é... Uma revolta muito grande, não é... Um gajo querer trabalhar, não... É uma revolta... Só as pessoas que passam por isto é que sabem a revolta que a gente sente... (Patrício, entrevista) 
Como eu estou, o senhor vê, eu se fosse a enxotar uma mosca da cara, não faço. [...] Sofre-se muito, sofre-se muito. Uma pessoa que anda em... - é o caso desses meus colegas que têm duas pernas artificiais - de qualquer maneira, eles sofrem, mas é diferente. Agora, eu, na situação em que estou, sofro muito, muito, muito. O senhor já viu... O senhor já reparou o que era um indivíduo pensar em construir uma família, em durante todo o tempo que Deus... fosse vivo, andar cá, levar uma vida, eu não digo totalmente só de gozo, mas levar uma vida diferente. Agora, vê-se nesta situação! [...] Primeiro que a gente acabe de me dar de comer, é uma coisa... Depois, ficar na cama, fechar a luz - eles fecharem-me a luz - e eu ficar na cama, e a única coisa que dá à gente é vontade de chorar. Porque, ninguém imagina o que é este sofrimento. (Tiago, entrevista)

Centrando-se nos eventos que causaram a deficiência nas longínquas frentes de combate, os DFA apresentam-se, mormente, como vítimas da história: instrumentos de uma Guerra cujos termos raramente percebiam e cuja justiça, hoje, poucos subscrevem. ${ }^{13}$ Pesem embora as diferentes visões políticas sobre a Guerra que constituem o universo dos Deficientes das Forças Armadas, pese embora a incipiente posição crítica que tendeu a marcar a hora da partida dos jovens combatentes, é lícito dizer que o universo dos Deficientes das Forças Armadas é dominado por um posicionamento de condenação da Guerra. Tal quadro deve-se, como acima referimos, a determinados fatores que nalguns casos se cumularam: deve-se à perspetiva histórica forjada seja pelo 25 de Abril, seja pelo reconhecimento que um pouco por todo o mundo veio a sancionar a legitimidade da senda anticolonial pela autodeterminação dos povos; deve-se ao confronto pessoal com a violência da Guerra e iniquidade do colonialismo; deve-se ao modo como a deficiência adquirida exacerbou a noção de uma Guerra sem sentido ou o sentimento de força descartável; deve-se, igualmente, como veremos à frente, ao modo como a própria AFDA se veio a estabelecer politicamente contra uma narrativa de celebração heroica, bem patente no mote que viria a ser consagrado: "A Força Justa das Vítimas de uma Guerra Injusta!". No entanto, atentando às muitas formas de aparição da violência nas experiências e narrativas que nos foram sendo confiadas, logo percebemos a insustentabilidade de uma narrativa que configure os DFA como

\footnotetext{
${ }_{13}$ O distanciamento em relação à justeza da Guerra exprime tanto o desconhecimento ou a incipiente formação política com que muitos dos DFA foram enviados para a Guerra, como exprimirá, igualmente, um processo posterior de renúncia a causas patrióticas anteriormente abraçadas: pelo impacto do sentimento de abandono e injustiça que se seguiu à deficiência; pelo modo como a ADFA se constitui com base numa ideologia, amplamente dominante, de uma condenação da Guerra; e pelo efeito da queda do regime ditatorial e dos seus "regimes de verdade".
} 
meras vítimas. São, muitas vezes, cumulativamente vítimas, perpetradores e testemunhas de violência. São vítimas da Guerra no sentido em que nela adquiriram deficiência, no sentido em que muitos lutaram um combate que nunca sentiram como seu, mas são vítimas paradoxais: porque foram parte de um exército imperialista, e porque muitas das suas histórias retratam-nos, igualmente, como perpetradores de violências.

No caso Marcelino, a memória arrasta a vitimação e a culpabilização numa mesma leva disruptiva. O efeito perturbador de um ato de violência que cometeu sobre um civil emergiu apenas em 2004, altura em que as imagens da Guerra do Iraque lhe vieram despertar as memórias da Guerra Colonial, obrigando-o a procurar apoio psiquiátrico:

Faz-me sofrer bastante. Acredito que, na altura, não tive problemas em fazer o que fiz [...] Não tive problema nenhum em fazer o que fiz. Mas hoje, penso que não os devia ter cometido, e isso afeta-me. Afeta-me e muitas vezes... por exemplo, à noite, quando estou com este zumbido, não é por acaso que de vez em quando, tenho de tomar o comprimido para dormir para... Hoje, estou ali sozinho, a pensar naquilo, e passo horas a chorar. Coisa que, na minha vida, não... eu não era choramingas, não... (Marcelino, entrevista)

Estamos, pois, perante histórias em que a possibilidade de exercer a violência desmedida, mesmo se não consumada, esteve sempre presente:

Que às vezes fala-se em chacinas. E dizem que os militares fazem isto, fazem aquilo. E eu... Todos nós somos capazes de fazer isso. Depende das oportunidades, depende das ocasiões. Eu, naquele momento, quando eu estava em plena operação de queimar aquela aldeia e de levar a população, se há alguém, se há, pronto, um tiro, ou uma..., alguém que estivesse..., um guerrilheiro que estivesse ali, que me desse um tiro, [palmada]. Nós matávamos a população, não tenho dúvidas nenhumas. Eu seria hoje... E pesar-me-ia, hoje na minha cabeça, uma chacina. Está a ver? A guerra é terrível. A guerra é terrível, porque me transforma em bicho, a matar ou morrer. (Juvenal, entrevista)

Nos relatos que nos foram sendo confiados, o impacto deferido pelos atos cometidos na Guerra prende-se com atos censuráveis cometidos sobre as populações enquanto episódios da violência da Guerra muitas vezes sob o ímpeto colérico de vingar a morte ou ferimento de um camarada ou de punir as populações por suspeita de conluio com o inimigo. De igual modo, estes momentos passíveis de reprovação posterior surgiam no trato com os prisioneiros. O relato de Hélio é disso bem impressivo: 
Estávamos emboscados há horas... com aquelas, aquela coisa, começa a raiar o dia, há um indivíduo que foi lá disparar, foi esse [... "alto, alto, ou faço fogo", o gajo não parou, ele atirou e apanhou aqui assim nas costas, e o homem ficou com a bexiga na mão...e o que ele levava não era arma nada, era uma pá daquelas do arroz, àquela hora ainda estava escuro parecia-nos uma arma...o homem aguentou duas horas com a bexiga na mão e veio no helicóptero até ao aquartelamento, chegou à enfermaria e tinha morrido um grande amigo meu, um furriel de Santarém, o [...], ainda estávamos, vários feridos, ainda estávamos debaixo daquela coisa, ficamos... porque, isto passou-se com alguns, porque havia lá, e esse indivíduo, pronto! Mas fomos para o aquartelamento e sabe o que lhe fizeram, com um giz fizeram-lhe um alvo e começaram com seringas a fazer tiro ao alvo na bexiga do homem (pausa) isto é horrível, não é? (pausa), mas não éramos nós... nós tínhamos sabido que na véspera tinham morrido indivíduos com uma faca, estávamos, tudo ali, a malta, esse o [...], não conseguimos tirá-lo debaixo do fogo, e no outro dia passámos lá e os abutres comeram-no todo... isto só visto. Estamos a falar de malta com vinte anos, nada justificava mas o facto é que... e estas cenas, estas cenas... o crime... é realmente um regime, um governo deixar que crianças, os alferes com 23 e 24 anos, os capitães tinham 25 anos e nós tínhamos 20 e havia-os lá com 19 e muita malta voluntária. Eu trabalhei com um agrupamento, açorianos, que cortavam línguas e orelhas, os açorianos são danados, e essa que eu apanhei, eles também tinham um medo deles, porque eles não faziam prisioneiros... matavam tudo, tudo... (Hélio, entrevista pessoal)

Esta consciência que nalguns DFA consagra uma autorreflexividade memorativa, que concilia o reconhecimento do próprio sujeito enquanto vítima e agressor, é diferentemente avivada pela noção do excesso e da responsabilidade pessoal, pela assunção do vazio de valores morais imposto pelo absurdo da guerra, ou pelo facto de o julgamento da história esmagadoramente definir Portugal como o agressor colonialista, anacronicamente travando os ventos da mudança. Muitas vezes a dificuldade de conciliar o reconhecimento da violência sofrida e a violência exercida justapõe-se, sem um encaixe estabilizado, à dificuldade no reconhecimento do DFA no seu ambíguo lugar de ex-combatente e crítico da violência colonial.

\section{Para uma memória pós-abissal}

Além da violência de deficiência infligida devido à Guerra Colonial, além da violência da discriminação imposta na nossa sociedade sobre as pessoas com deficiência, os DFA confrontaram-se durante a parte mais significativa das suas vidas com a violência do silenciamento das suas experiências, marcadas que foram por uma Guerra que, antes e depois do 25 de Abril, foi "interditada" do espaço e do debate público. Ainda que o espaço associativo como 
o da ADFA, ou o espaço convivial dos jantares de batalhão ou de companhia recuperem essas experiências, socializando-as, isso acontece mormente num circuito relativamente fechado. A solidão da vivência e da marca traumática da Guerra (corpórea ou memorativa) foi e é continuadamente experimentada nas suas vidas sociais quotidianas (família, trabalho, comunidades de residência). Não obstante o reconhecimento das trajetórias particulares que engendraram um longo desencontro entre a memória vivida da Guerra Colonial e o justo reconhecimento da centralidade histórica deste conflito, acreditamos que, em última instância, a incomodidade "fantasmática" trazida ao corpo social pelos DFA reflete algo de mais fundo. Referimo-nos ao modo como no Ocidente a experiência colonial persiste sendo ativamente produzida como inexistente, ou trivializada sob alegações de "generosidade civilizatória" ou sob o heroísmo expansionista, inscritos nas diferentes narrativas nacionais europeias (Santos, 2013; Lourenço, 2014), numa óbvia perpetuação daquilo a que Boaventura define como as "linhas abissais da modernidade" (Santos, 2007). Tudo se passa como se os discursos que criaram e tentaram manter intactas as "províncias ultramarinas" tivessem, afinal, vingado em transformá-las em "províncias finitas de significado" (Schutz, 1970: 252), neste caso mundos de sentido singularmente povoados pela guerra e pelo racismo, ainda embargados na fronteira que outrora definia o abismo entre metrópoles e colónias.

Ao definir o pensamento moderno como abissal, Boaventura de Sousa Santos enfatiza como persistem ainda os mecanismos que, separando sociedades metropolitanas e territórios coloniais, desqualificam e invisibilizam as experiências e saberes tidos como imanentes à zona colonial (Santos, 2007). Nesse sentido, geram-se

distinções invisíveis [que] são estabelecidas através de linhas radicais que dividem a realidade social em dois universos distintos: o universo "deste lado da linha" e o universo "do outro lado da linha". A divisão é tal que "o outro lado da linha" desaparece enquanto realidade, torna-se inexistente, e é mesmo produzido como inexistente. Inexistência significa não existir sob qualquer forma de ser relevante ou compreensível. (ibidem: 3-4)

$\mathrm{Na}$ mesma nota da proposta de Boaventura de Sousa Santos, creio que podemos falar de uma memória abissal para caracterizar o modo como a experiência colonial, naquilo que tem de mais característico - a violência que a sustenta -, se encontra ausente nas histórias que constituem, no Norte, as narrativas sobre o "outro lado da linha”. É esta memória abissal que consente historiografias nacionais em que a relação com o Sul global 
é silenciada ou dobrada aos mitos fundadores que a um tempo expurgam o sofrimento produzido pela senda colonial, renegam a permanência das suas lógicas e produzem a não existência dos sujeitos que a testemunham. A valorização do sofrimento segue, sem dúvida, linhas raciais que tiram do tempo, minimizando, as vítimas africanas da Guerra e da violência colonial, convenientemente longínquas, virtualmente inexistentes para a memória do Portugal metropolitano. Quanto aos DFA de origem portuguesa, aqueles que regressaram após a Guerra, outros foram os mecanismos que permitiram afirmar a sua inexistência enquanto testemunhas da Guerra Colonial: a erradicação da Guerra do espaço público, a permanência do mito lusotropicalista e a exclusão de vozes e experiências marcadas pelo estigma da deficiência. Entre mundos, os DFA estão na "sociedade metropolitana" mas não lhe pertencem inteiramente conquanto carregam memórias embargadas, porque vindas dos "territórios coloniais", que permanecem, segundo a sentença hegemónica a Norte, como territórios de boa ou de não memória. Nesse sentido, os DFA, embora portugueses e residentes em Portugal, são proverbialmente estrangeiros à memória política que no Ocidente - por se constituir enquanto dominante - pôde esquecer do colonialismo a violência que lhe foi imanente. Como refere Robert Young, refletindo sobre autores que tratam o colonialismo em diferentes lugares, "[a] diferença é menos uma questão de geografia do que o lugar, político e cultural, de onde os indivíduos falam, para quem falam e como definem o seu lugar de enunciação" (2001: 62).

Além do lugar político e cultural que tendencialmente constitui os DFA enquanto vozes de denúncia de uma Guerra esquecida, eles são ontologicamente marcados por uma posição corpórea em que a Guerra se inscreve de forma irredimível. Tudo se passa como se o "acordo tácito" de diluir a memória da violência colonial, vigente ordem política das sociedades ex-metropolitanas, fosse desdito por "estilhaços humanos" que, atravessando a linha abissal, carregam consigo histórias que deveriam ter ficado convenientemente longínquas nas colónias distantes, em corpos que o racismo mais facilmente desqualificaria como indignos de uma voz sofrida.

A memória pós-abissal, alego, é aquela cujo olhar para o passado inscreve a violência colonial no centro da narrativa histórica da modernidade. A memória pós-abissal é aquela que identifica a memória abissal enquanto um segundo fôlego da violência colonial, uma violência que opera pelos seguintes mecanismos: a racialização do valor da vida humana; a elisão dos testemunhos que expõem as misérias produzidas pelo longo tempo do colonialismo; e a desqualificação das memórias vindas "do outro lado da linha”. Uma memória pós-abissal da violência terá que ser capaz de conter 
as vastas latitudes da experiência moderna, os vastos suis, carregando corpos e violências, mortos e sobreviventes, reconstituindo, a Norte e Sul, ${ }^{14}$ os estilhaços de uma violência que está longe de ter cessado.

As narrativas dos DFA, no modo paradoxal como nos permitem aceder à violência colonial, constituem uma perspetiva muito particular de uma gramática mais ampla que nos instiga à busca de diálogos e de sujeitos que, a Sul, nos trazem de latitudes onde o esquecimento da senda colonial nunca chegou a ser uma hipótese.

\section{Referências bibliográficas}

ADFA - Associação dos Deficientes das Forças Armadas (1999), ADFA 25 anos: 1974-1999. Lisboa: Associação dos Deficientes das Forças Armadas.

Albuquerque, Afonso; Lopes, Fani (1994), "Características de um grupo de 120 combatentes da Guerra Colonial vítimas de stress de guerra”, Vértice, 58, 28-32.

Anderson, Benedict (1983), Imagined Communities: Reflections on the Origin and Spread of Nationalism. London: Verso.

Antunes, José Freire (1996), A Guerra de África: 1961-1974, 2 vol. Lisboa: Temas e Debates. Barkan, Elazar (2001), The Guilt of Nations: Restitution and Negotiating Historical Injustices. New York: Norton.

Barnes, Colin (2003), "What a Difference a Decade Makes: Reflections on Doing 'Emancipatory' Disability Research”, Disability \& Society, 18(1), 3-17.

Cann, John (2005), Contra-subversão em África: como os portugueses fizeram a guerra em África. Tradução de Renato Pinto. Lisboa: Prefácio.

Castelo, Cláudia (2007), Passagens para África: o povoamento de Angola e Moçambique com naturais da metrópole (1920-1974). Porto: Afrontamento.

Coelho, João Paulo Borges (2003), "Da violência colonial ordenada à ordem pós-colonial violenta: sobre um legado das Guerras Coloniais nas ex-colónias portuguesas", Lusotopie, 175-193.

Connerton, Paul (1989), How Societies Remember. Cambridge: Cambridge University Press.

Das, Veena; Kleinman, Arthur (2001), "Introduction”, in Arthur Kleinman; Veena Das; Margaret Lock; Mamphela Ramphele; Pamela Reynolds (orgs.), Remaking a World: Violence, Social Suffering and Recovery. Berkeley: University of California Press, 1-30. French, Lindsay (1994), "The Political Economy of Injury on the Thai-Cambodia Border", in Thomas Csordas (org.), Embodiment and Experience: The Existential Ground of Culture and Self. Cambridge: Cambridge University Press.

${ }_{14}$ No que à Guerra Colonial/ Guerra de Libertação diz respeito, um interessante exemplo deste possível diálogo deu-se com a 1. ${ }^{a}$ Conferência de Antigos Combatentes de Portugal, Angola, Moçambique e Guiné-Bissau”, organizada pela ADFA em 1990 (cf. Jornal Elo, maio de 1990, n. ${ }^{\circ} 188$ ). 
Fontes, Fernando (2009), "Pessoas com deficiência e políticas sociais em Portugal: da caridade à cidadania social”, Revista Crítica de Ciências Sociais, 86, 73-93.

Gomes, Carlos de Matos (2013), “A africanização na Guerra Colonial e as suas sequelas. Tropas locais - Os vilões nos ventos da História”, in Maria Paula Meneses; Bruno Sena Martins (orgs.), As Guerras de Libertação e os sonhos coloniais: alianças secretas, mapas imaginados. Coimbra: Almedina: 123-142.

Hacking, Ian (1996), "Memory Sciences, Memory Politics", in Paul Antze; Michael Lambek (orgs.), Tense Past: Cultural Essays in Trauma and Memory. New York: Routledge.

Hahn, Harlan (2002), "Debates and Political Advocacy: The US Disability Movement", in Mike Oliver; Len Barton (orgs.), Disability Studies Today. Cambridge: Polity Press, 162-189.

Kirmayer, Laurence (1996), "Landscapes of Memory: Trauma, Narrative, and Dissociation”, in Paul Antze; Michael Lambek (orgs.), Tense Past: Cultural Essays in Trauma and Memory. New York: Routledge: 173-198.

Ingstad, Benedict; Whyte, Susan (orgs.) (1995), Disability and Culture. Berkeley: University of California Press.

LaCapra, Dominick (2001), Writing History, Writing Trauma. Baltimore: Johns Hopkins University Press.

Lourenço, Eduardo (2014), Do colonialismo como nosso impensado. Organização e prefácio de Margarida Calafate Ribeiro e Roberto Vecchi. Lisboa: Gradiva.

Martins, Bruno Sena (2006), E se eu fosse cego: narrativas silenciadas da deficiência. Porto: Afrontamento.

Martins, Bruno Sena (2008), "The Suffering Body in the Cultural Representations of Disability: The Anguish of Corporal Transgression", in Thomas Campbell; Fernando Fontes; Armineh Soorenian; Chris Till (orgs.), Disability Studies: Emerging Insights and Perspectives. Leeds: The Disability Press, 93-107.

Martins, Bruno Sena (2013), Sentido Sul: a cegueira no espírito do lugar. Coimbra: Almedina. Maurício, Jorge (1994), "A Guerra Colonial, os Deficientes das Forças Armadas e a ADFA", Vértice, 58, 25-27.

Meneses, Maria Paula; Gomes, Catarina Antunes (2013), "Regressos? Os retornados na (des)colonização portuguesa”, in Maria Paula Meneses; Bruno Sena Martins (orgs.), As Guerras de Libertação e os sonhos coloniais: alianças secretas, mapas imaginados. Coimbra: Almedina: 59-107.

Oliver, Michael (1990), The Politics of Disablement. Houndmills: The Macmillan Press. Quintais, Luís (2000), As guerras coloniais portuguesas e a invenção da História. Lisboa: ICS.

Ricoeur, Paul (2004), Memory, History, Forgetting. Chicago: University of Chicago Press. Santos, Boaventura de Sousa (2007), "Para além do pensamento abissal: das linhas globais a uma ecologia de saberes”, Revista Crítica de Ciências Sociais, 78, 3-46. 
Santos, Boaventura de Sousa (1999), Pela mão de Alice: O social e o político na pós-modernidade. Porto: Afrontamento.

Santos, Boaventura de Sousa (2013), "Prefácio", in Maria Paula Meneses; Bruno Sena Martins (orgs.), As Guerras de Libertação e os sonhos coloniais: alianças secretas, mapas imaginados. Coimbra: Almedina.

Santos, Boaventura de Sousa (2014), Epistemologies of the South: Justice against Epistemicide. Boulder: Paradigm Publishers.

Santos, Boaventura de Sousa; Nunes, João Arriscado (2004), "Introduction: Democracy, Participation and Grassroots Movements in Contemporary Portugal", South European Society \& Politics, 9(2), 1-15.

Schutz, Alfred (1970), On Phenomenology and Social Relations; Selected Writings. Chicago: University of Chicago Press.

Turner, Victor (1967), The Forest of Symbols: Aspects of Ndembu Ritual. Ithaca: Cornell University Press.

Young, Robert (2001), Postcolonialism: An Historical Introduction. Oxford: Blackwell Publishers.

Artigo recebido a 11.09.2014

Aprovado para publicação a 19.01.2015

\section{Bruno Sena Martins}

Centro de Estudos Sociais, Universidade de Coimbra

Colégio de S. Jerónimo, Largo D. Dinis, Apartado 3087, 3000-995 Coimbra, Portugal

Contacto: bsenamartins@ces.uc.pt 
